\title{
Increasing fire activity in a warming climate? Ice core record insights from the present and the last interglacials
}

Natalie Kehrwald ${ }^{1}$, P. Zennaro ${ }^{1,2}$ and C. Barbante ${ }^{1,2}$

'Department of Environmental Sciences, Informatics and Statistics, University of Venice, Italy; kehrwald@unive.it

2 Institute for the Dynamics of Environmental Processes, Consiglio Nazionale delle Ricerche, Venice, Italy

Fire impacts climate by changing atmospheric greenhouse gas concentrations, vegetation distributions, and surface albedo. We present a biomarker, levoglucosan, to reconstruct past fire activity from ice cores. This tracer allows us to investigate fire and climate interactions over glacial-interglacial cycles.

\begin{abstract}
The devastating Waldo Canyon fire (North America) forced the evacuation of approximately 30,000 people from their homes in Colorado Springs during June 2012 (Fig. 1). The massive wildfires and associated heat wave that swept across Russia in 2010 were responsible for the deaths of over 55,000 people (Barriopedro et al. 2011), caused 15 billion US dollars in damages and were the result of both natural and anthropogenic climate change (Otto et al. 2012). This destruction demonstrates the importance of understanding the prospect of increased fire activity in a changing climate.
\end{abstract}

\section{Interactions between climate and fire activity}

The relative impact of climate change (including increased deadwood availability due to bark beetle infestations) and human activity on fires (including forest management and housing expansion) can differ between individual fires. Droughts tend to increase fire activity, provided that there is sufficient material to burn. Increased precipitation may also cause more vegetation growth and increase the area susceptible to burning as long as the precipitation remains low enough that it does not suppress fires. Regional fire activity, therefore, depends on a number of variables including temperature, fuel availability, and precipitation, but generally increasing global temperatures enhance global fire activity (Daniau et al. 2010; Power et al. 2008).

Fires in turn, influence climate by emitting greenhouse gases and aerosols into the atmosphere, and by affecting carbon sequestration in vegetation and soils. Deforestation fires alone have caused $\sim 19 \%$ of the anthropogenic warming since preindustrial times (Bowman et al. 2009). Currently, total biomass burning releases up to $50 \%$ as much carbon dioxide into the atmosphere as does fossil fuel combustion (Bowman et al. 2009). The impact of biomass burning emissions on the global radiation balance and the carbon cycle, however, remains one of the least understood aspects of the climate system.

It is essential to determine the interactions between climate and fire activity through time in order to establish if humans are increasing susceptibility to fire in a warming climate. The last interglacial period (LIG, 130-116 ka BP), represents a climate analogous to the present but without the impact of human activity. Ice core records from the LIG and present interglacial contain contemporaneous climate and fire proxies that allow a detailed assessment of fire activity in warming climates with and without anthropogenic influences.

\section{Fire and climate records in ice cores}

Researchers have developed many fire proxies in ice cores during the past decade. Tracers for biomass burning in ice cores with atmospheric residence times ranging from days to weeks include black carbon, particulate organic carbon, monosaccharide anhydrides, organic acids, diacids (oxalate, formate), major ions (ammonium and potassium), isotopes of carbon monoxide and methane, polycyclic aromatic hydrocarbons, and charcoal. In general, the shorter residence time tracers provide more regional records, while the longer residence time tracers can provide hemispheric to global records of biomass burning. Here, we discuss using monosaccharide anhydrides as fire tracers and their applicability to the present and past interglacials.

Biomass burning injects monosaccharide anhydrides such as levoglucosan into the fine particle phase of smoke plumes. Levoglucosan is a specific tracer of fire activity as it is only derived from cellulose burning at temperatures greater than $300^{\circ} \mathrm{C}$
(Schkolnik and Rudich 2006; Simoneit 2002). Levoglucosan is injected into and travels through the atmosphere in smoke plumes before returning to the surface through wet and dry deposition (Fraser and Lakshmanan 2000; Stohl et al. 2007). We trace levoglucosan from a forest fire source to its deposition on glacier surfaces where it is preserved and does not appear to decompose in snow and firn layers (Fig. 2A; Kehrwald et al. 2012). Levoglucosan is unequivocally a cellulose degradation product (Simoneit 2002), while other biomass burning tracers archived in snow and ice cores may have multiple sources.

We investigated samples from a snow pit at the Summit camp in Greenland and combine levoglucosan records with other biomass burning proxy records to provide an analysis of past fire activity from 1987 to 1995 (Fig. 2B-C). We demonstrate that combining levoglucosan concentrations with other biomass burning proxies helps determine the relative contribution of fire versus other sources to total deposition. This is illustrated by an event that occurred between spring 1994 and spring 1995:

- The oxalate and levoglucosan peaks replicate the same known Canadian fire event (Fig. 2C). Although oxalate is a product of forest fire emissions (Legrand and DeAngelis 1996) it may also originate from vehicle emissions (Kawamura and Kaplan 1987).

- Ammonium concentrations in the snow pit also peak during the fire event, but the

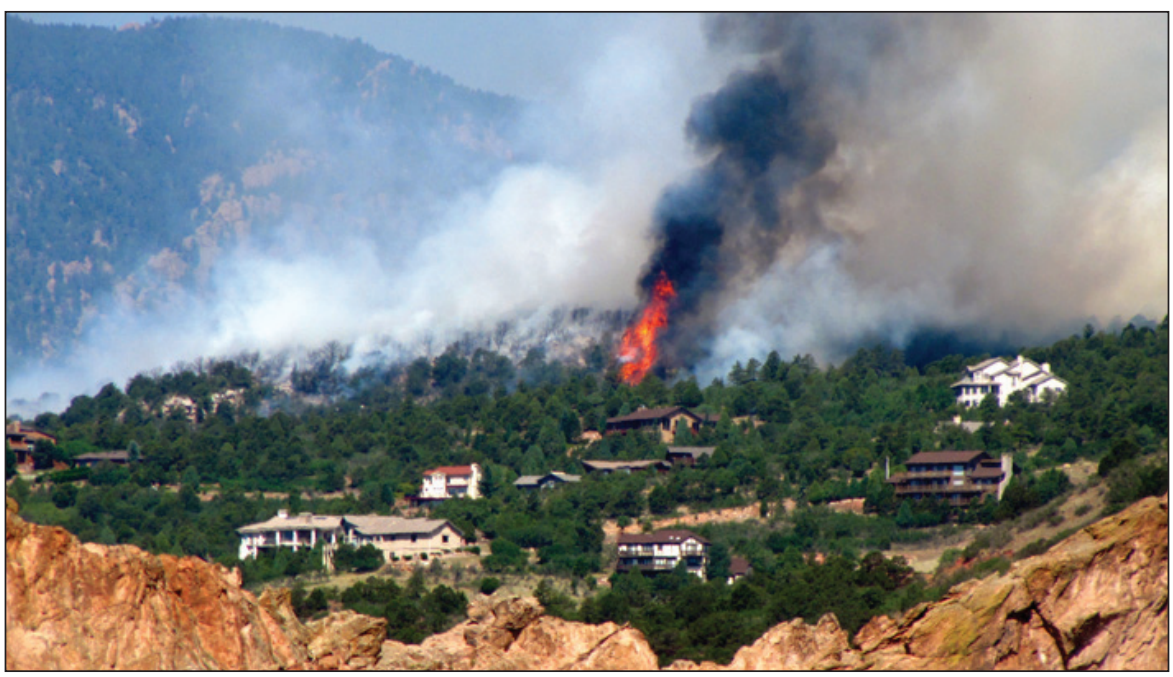

Figure 1: Waldo Canyon fire in Colorado Springs, Colorado, USA ( June 27, 2012). Photo: Erica Rewey 


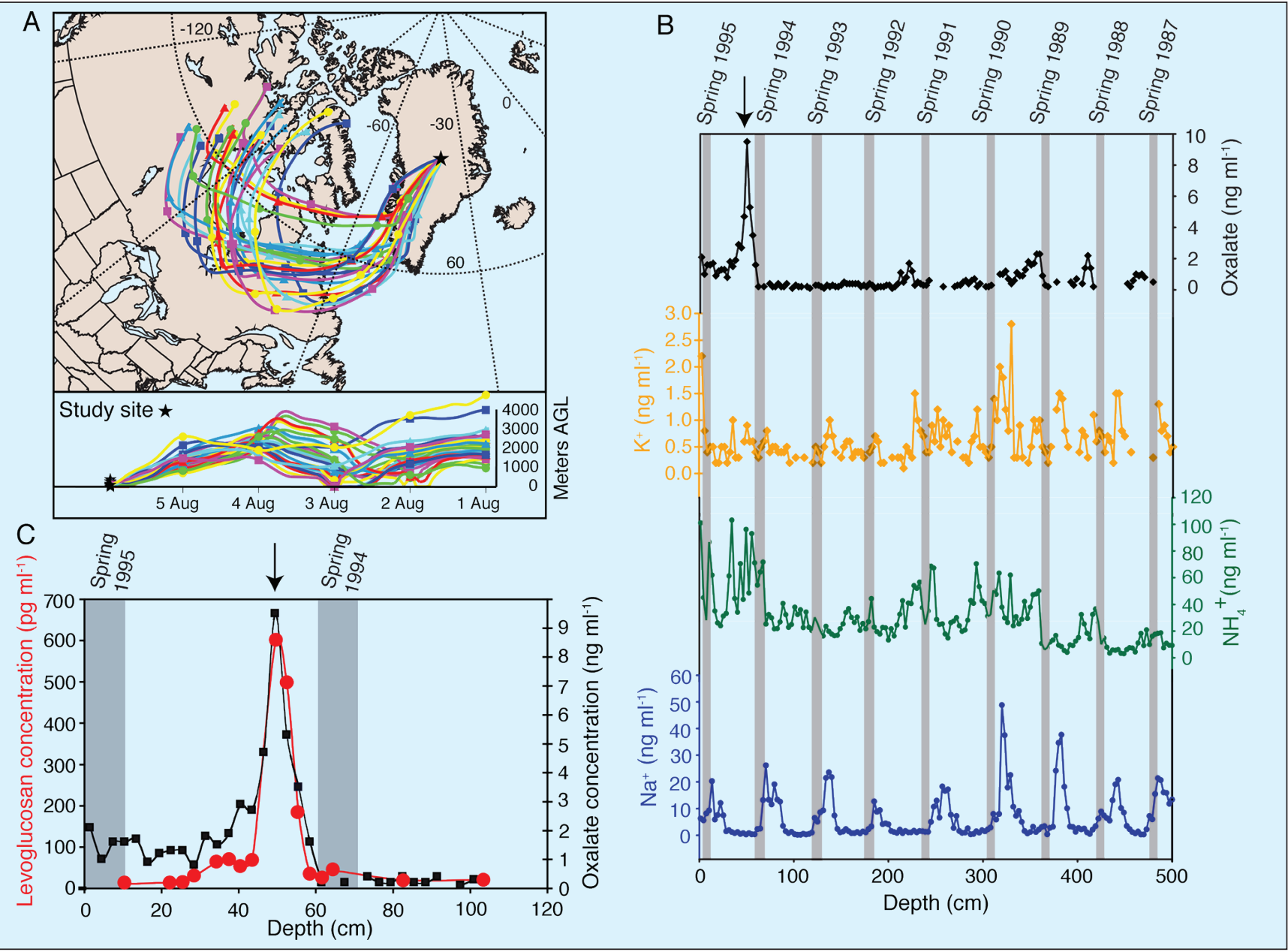

Figure 2: $\boldsymbol{A}$ ) Atmospheric transport of smoke plumes from the western Hudson Bay forest fire source to the study site (AGL = above ground level). B) Multiple years of fire markers (ammonium, potassium, and oxalate) determined from a 6-m deep snow pit at Summit, Greenland. Note that the sodium concentration record, also shown, is one of the main tools to date the snow pit (peaks in sodium denote spring accumulation). C) Comparison between oxalate and levoglucosan as biomass burning tracers in the upper section of the snow pit. The black arrows on (B) and (C) point to the same known Canadian fire event. Figure modified from Kehrwald et al. (2012).

increased concentrations are distributed across a relatively wide depth range (Fig. 2B). Elevated concentrations of ammonium (Stohl et al. 2007) may reflect past fires, but atmospheric ammonium may also result from lightning, marine sources, soil processes, or agricultural activity (Hristov et al. 2011; Olivier et al. 2006).

-While potassium concentrations have been identified as a past fire activity proxy (Echalar et al. 1995) they do not reproduce the oxalate and levoglucosan peaks in our record (Fig. 2B). Potassium can be transported to glacier surfaces through sea salts and mineral aerosols (Laj et al. 1997). The differing transport paths and sources of levoglucosan and potassium are reflected in the snow pit concentrations. As a result, if the fire reconstruction from this snow pit were assessed solely from potassium concentrations, they would miss an important fire event.

The research team at the University of Venice has created high-resolution Holocene levoglucosan records from the NEEM and EPICA Dome C (EDC) ice cores and a late Holocene levoglucosan record from Kilimanjaro ice cores. This combination creates a pole-equator-pole transect of Holocene fire records. The Kilimanjaro ice fields are located near the largest savanna system in the world. Savanna and similar grassland fires produce the highest levoglucosan emission factors of various tested vegetation types (Engling et al. 2006) and Kilimanjaro may serve as reference site for high levoglucosan concentrations. NEEM and EDC are located farther away from levoglucosan sources than Kilimanjaro, but both of these polar locations archive a levoglucosan flux above the detection limit. Late Holocene NEEM levoglucosan concentrations correlate with synthesized charcoal records above $55^{\circ} \mathrm{N}$, demonstrating the viability of using levoglucosan concentrations in ice cores as a biomass burning tracer over centennial to millennial timescales. This correlation between sedimentary charcoal and ice core records allows researchers to reconstruct fire histories over larger spatial scales.

The research team is currently determining LIG levoglucosan concentrations from NEEM and EDC ice cores to compare with the Holocene records. Initial tests are encouraging and demonstrate that the LIG ice contains detectable levoglucosan concentrations.

\section{Outlook}

Human activities including slash-and-burn farming, forest fires caused by human ignition, and wildfire suppression alter global fire activity. Anthropogenic activity also increases greenhouse gas concentrations, resulting in warming temperatures and possibly increased wildfires. Paleorecords demonstrate that global fire activity is higher during interglacials than during glacial periods in a purely natural system (Daniau et al. 2010). Imminent measurements of LIG levoglucosan concentrations will provide unique constraints on past fire activity in a warming climate with implications for fire activity in the current climate.

\section{Acknowledgements}

The research leading to these results has received funding under grant agreement no 267696, (ERC-2010-AdG_20100224) "EARLYhumanIMPACT. How long have humans been impacting the climate system?".

\section{Selected references}

\section{Full reference list online under:}

http://www.pages-igbp.org/products/newsletters/ref2013_1.pdf

Bowman DMJS et al. (2009) Science 324: 481-484

Engling G et al. (2006) Atmospheric Environment 40: 299-311

Kehrwald N et al. (2012) Tellus B 64, doi: http://dx.doi.org/10.3402/ tellusb.v64i0.18196

Schkolnik G, Rudich Y (2006) Analytical and Bioanalytical Chemistry 385 : 26-33

Simoneit BRT (2002) Applied Geochemistry 17: 129-162 